\title{
Diagnosis and acute management of patients with concussion at children's hospitals
}

\author{
Jeffrey D Colvin, ${ }^{1}$ Cary Thurm, ${ }^{2}$ Brian M Pate, ${ }^{1}$ Jason G Newland, ${ }^{3}$ Matt Hall, ${ }^{2}$ \\ William P Meehan III ${ }^{4,5,6,7}$
}

- Additional material is published online only. To view please visit the journal online (http://dx.doi.org/10.1136/ archdischild-2012-303588).

1 Department of Pediatrics, Division of Pediatric Hospital Medicine, Children's Mercy Hospitals and Clinics, University of Missouri-Kansas City, Kansas City, Missouri, USA

${ }^{2}$ Department of Informatics, Children's Hospital Association, Overland Park, Kansas, USA ${ }^{3}$ Department of Pediatrics, Division of Infectious Disease, Children's Mercy Hospitals and Clinics, University of MissouriKansas City, Kansas City, Missouri, USA

${ }^{4}$ The Micheli Center for Sports Injury Prevention, Waltham, Massachusetts, USA

${ }^{5}$ Sports Concussion Clinic, Division of Sports Medicine, Children's Hospital Boston, Boston, Massachusetts, USA ${ }^{6}$ Division of Emergency Medicine, Children's Hospital Boston, Boston Massachusetts, USA

${ }^{7}$ Brain Injury Center, Children's Hospital Boston, Boston, Massachusetts, USA

\section{Correspondence to} Dr Jeffrey D Colvin, Section of Pediatric Hospital Medicine, Children's Mercy Hospital, 2401 Gillham Road, Kansas City, MO 64108-4619, USA jdcolvin@cmh.edu

Received 30 December 2012 Revised 3 June 2013 Accepted 17 June 2013 Published Online First 13 July 2013

\section{SLinked}

- http://dx.doi.org/10.1136 archdischild-2012-302820

- http://dx.doi.org/10.1136/ archdischild-2013-304436

To cite: Colvin JD Thurm C, Pate BM, et al. Arch Dis Child

2013;98:934-938.
ABSTRACT
Objectives To describe the number of hospital admissions for concussion at paediatric hospitals in the USA. To describe the use of imaging and medications for acute concussion paediatric patients.

Design Cross-sectional study.

Setting Children's hospitals participating in the Pediatric Health Information System in the USA during a 10-year period.

Patients All emergency department (ED) visits and inpatient admissions with the primary diagnosis of concussion, defined as International Classification of Diseases, Ninth Revision, Clinical Modification codes for: (1) concussion, (2) postconcussion syndrome or (3) skull fracture without mention of intracranial injury with concussion.

Main outcome measures The proportion of concussion patients who were hospitalised, underwent imaging or received medication, and the adjusted costs of visits for concussion.

Results The number of ED visits for concussion increased between 2001 and 2010 (2126 (0.36\% of all ED visits) vs 4967 ( $0.62 \%$ of all ED visits); $p<0.001)$, while the number of admissions remained stable. Of ED visits for concussion, $59.9 \%$ received CT and $47.7 \%$ received medications or intravenous fluids. Non-narcotic analgesics were the most common medication administered. Adjusted costs of patient visits were significantly higher when imaging was obtained (US\$695, IQR US\$472-\$1009, vs US\$191, IQR US\$114-\$287). An ED visit with CT, however, cost less than a hospitalisation without CT (US\$1907, IQR US\$1292-\$3770).

Conclusions Although the number of ED patients diagnosed with concussion has increased, the number admitted has remained stable. Concussion patients at paediatric hospitals in the USA commonly undergo CT imaging and receive medication.

\section{INTRODUCTION}

Concussion is defined as 'a complex pathophysiological process affecting the brain, induced by biomechanical forces', which transmits an 'impulsive force to the head', resulting in 'rapid onset of shortlived impairment of neurologic function', reflecting 'functional disturbance rather than structural injury', and in which no abnormality is seen 'on standard structural neuroimaging studies.' 1 The recognition of long-term health problems resulting from multiple concussions has led to increased medical and media attention. $^{2}$ Up to 3.8 million sport-related traumatic brain injuries (TBI) occur annually in the USA, the vast majority of which are concussions. ${ }^{3}{ }^{4}$ Given the high number of children participating in sports,

\section{What is already known on this topic?}

- Multiple concussions are increasingly associated with long-term health problems.

- The annual number of paediatric emergency department (ED) visits for concussion has dramatically increased.

- ED visits for paediatric concussion patients are often associated with CT imaging of the head.

\section{What this study adds?}

- Approximately 1 of every 160 patients reporting to a paediatric hospital emergency department (ED) is diagnosed with concussion, a proportion that has doubled in the last decade.

- Although ED visits for paediatric concussion at children's hospitals are increasing, inpatient admissions for paediatric concussion have remained stable.

- Besides CT imaging, concussion patients in the ED also frequently receive intravenous fluids and analgesics.

the potential for complications due to repeated sport-related concussions is cause for concern. ${ }^{2} 56$ Conservatively, 173000 children report to US emergency departments (ED) each year with a concussion due to sports and recreation activities alone. ${ }^{7}$ Annually, paediatric inpatient admissions for concussion due to sports alone result in over US\$6 million in hospital charges in the USA. ${ }^{8}$

Studies have documented a dramatic increase in the number of annual paediatric ED visits due to concussion in recent years. ${ }^{7} 9$ Previous investigations show that the number of children seeking care for concussions in EDs in the USA has increased over the past decade. ${ }^{7} 9$ Prior studies have also demonstrated that a substantial proportion of paediatric patients diagnosed with a concussion undergo CT. ${ }^{10} 11$

While these investigations have given insight into current medical practices for diagnosing and managing paediatric concussions, the frequency of medication administration in the hospital setting and acutely after concussion remains unknown. ${ }^{12}{ }^{13}$ Furthermore, it is unclear whether the increasing number of ED visits for paediatric concussions is 
mirrored by a similar increase in the number of inpatient admissions for paediatric concussion.

The objectives of this study were: (1) to determine the number of hospital admissions due to concussion over a 10-year period and (2) to determine the use of imaging and medications in managing acute concussion patients at paediatric hospitals in the USA.

\section{METHODS}

We conducted a cross-sectional study using the Pediatric Health Information System (PHIS). The PHIS is an administrative database of the Children's Hospital Association and contains inpatient, observation unit and ED data from 43 freestanding children's hospitals in the USA. Hospitals participating in the PHIS database are located in all regions of the USA, typically in large urban areas. Hospitals submit patient data, including demographic, payer, resource use (such as procedures and medications) and episode of care information (admission date, repeat hospitalisation), as well as International Classification of Diseases, Ninth Revision, Clinical Modification (ICD-9-CM) codes. Validating the quality of the PHIS data is a joint effort among the Children's Hospital Association, the participating hospitals, and the data warehouse vendor (Thomson Reuters, New York City, USA). Validity and reliability checks are performed, and data are included in PHIS only when classified errors occur in $<2 \%$ of a hospital's quarterly data.

\section{Study population}

We included patients 18 years old or younger with a primary ICD-9-CM discharge code for: (1) concussion (850.x), (2) postconcussion syndrome (310.2) or (3) skull fracture without mention of intracranial injury with concussion $(800.09,800.59$, $801.09,801.59,803.09,803.59,804.09$, 804.59). We did not include patients with the ICD-9-CM codes for skull fracture (800.xx-804.xx), head injury unspecified (959.01), other brain injury $(854 \mathrm{xx})$ and intracranial injury of other and unspecified nature (854.xx) unless they were also diagnosed with a concussion as defined above, as we could not be certain that patient with such codes sustained concussions.

A concussion was categorised as sport-related only if the patient had one of the following external cause of injury codes: E001-E010 (activities involving sports), E885.0-885.4 (falls from non-motorised scooter, roller skates, skateboard, skis or snowboard), E886.0 (fall in sports), E917.0 (struck in sports), E917.5 (struck in sports with subsequent fall), E910.0-E910.2 (drowning or submersion from waterskiing or other sports) and E828 (animal being ridden injuring pedestrian).

In order to assess trends over time, we examined patient encounters at 14 children's hospitals reporting data to PHIS over a 10-year study period, from 1 January 2001 through 31 December 2010. Because children's hospitals have gradually started supplying data to the PHIS database overtime, only 14 hospitals had available data beginning in 2001. In order to describe current assessment and management practices, we examined data collected during a 30 -month period from 1 April 2007 to 30 September 2009 that contained data from 30 children's hospitals. This more recent 30 -month period was selected in order to include a larger number of children's hospitals submitting data to PHIS by mid-2007. For patients with subsequent admissions to the ED within 30 days of a prior admission, only the index admission was analysed. Only patients admitted through the ED were included for the analysis of inpatient and observation hospitalisations, as we could not access data regarding imaging, medication and neurocognitive testing received prior to admission for patients admitted directly. Similarly, we did not examine data for patients who had been assessed and managed at other EDs prior to referral to the studied PHIS children's hospitals.

\section{Measured outcomes}

We examined all ED patients with the primary diagnosis of concussion, who were hospitalised, who received imaging, who were given medications and who sustained sport-related concussions. Furthermore, we assessed changes in the number of visits and the number of admissions for concussion patients over the most recent 10 years available.

Patient demographic information and insurance type were queried. The adjusted costs of patient visits were calculated. In order to calculate adjusted costs, the actual charges recorded in PHIS were adjusted by the United States' Centers for Medicare and Medicaid price/wage index for each hospital location and hospital-level cost-to-charge ratios. ${ }^{14} 15$

\section{Data analysis}

Descriptive and univariate statistics were used to describe the study population. All proportions are presented as percentages with $95 \%$ CIs. For comparisons between groups, $\chi^{2}$ analyses were used for all categorical variables and Student's $t$ tests were used for continuous variables. When comparisons of continuous variables were made between more than two groups, one-way analysis of variance was used. The annual trend from 2001 to 2010 in the number of ED patients diagnosed with concussion was modelled using piecewise linear regression with an inflection point at 2007 based on visual inspection. The trend in the number of concussion patients admitted was modelled with linear regression. Inferences for trends were based on slopes of the resulting regression lines. All analyses were performed using SAS V.9.3 (SAS Institute, Cary, North Carolina, USA). Statistical significance was defined as $\mathrm{p}<0.05$.

\section{RESULTS}

\section{Trend in diagnosis and admission (10-year study period)}

The number of ED patients diagnosed with concussion increased over the 10-year study period from 2126 of 592119 ED visits in 2001 to 4967 of 807695 in 2010 (figure 1). The trend in the number of ED patients with concussion rose sharply beginning in 2007, with a higher annual change in the period 2007-2010 compared with the period 2001-2007 (559 vs 147 patients per year; $p<0.001)$. A concomitant increase in the percentage of all ED patients diagnosed with concussion was also observed, from $0.36 \%(95 \%$ CI $0.34 \%$ to $0.37 \%$ ) in 2001 to $0.62 \%$ (95\% CI $0.60 \%$ to $0.63 \%$ ) in 2010 . In contrast, the number of patients admitted from the ED with concussion remained stable with 525 admissions in 2001 and 555 admissions in 2010 (figure 1).

\section{Assessment and management of concussion patients (30-month study period)}

During the 30-month study period, there were 3936591 ED visits recorded for 30 hospitals in PHIS, of which 20806 (0.53\%; $95 \%$ CI $0.52 \%$ to $0.54 \%$ ) received a primary diagnosis of concussion. The mean age of patients diagnosed with concussion was 9.6 years (95\% CI 9.55 to 9.69 ); most were male (table 1 ). Nearly three-quarters of all concussion patients were between the ages of 6 and 18 years (table 1). Concussion patients were more likely to be privately insured than non-concussion patients (table 1). Of the $14383(69.1 \%)$ visits for concussion that had an associated E-code recorded, $23.2 \%$ (95\% CI $22.6 \%$ to $24.0 \%)$ were sport-related. 
Figure 1 Over the 10-year study period, the number of emergency department visits recorded in the Pediatric Health Information System with a primary diagnosis of concussion increased significantly $(p<0.001)$ while the number of paediatric concussion patients admitted to the hospital remained relatively stable with 525 admissions in 2001 and 555 admissions in 2010.

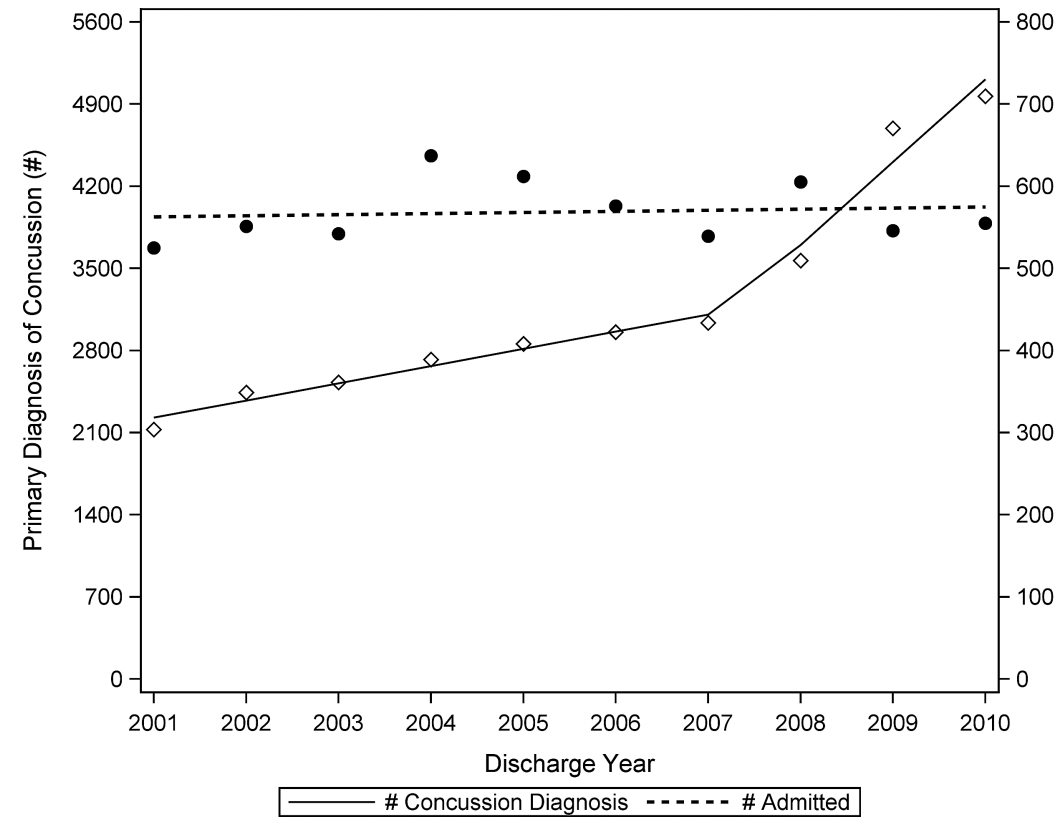

concussion. Of patients with the primary diagnosis of concussion, only 46 patients $(0.22 \%, 95 \%$ CI $0.17 \%$ to $0.29 \%)$ had a secondary diagnosis for intracranial injury.

\section{DISCUSSION}

Our study suggests that approximately 1 out of every 160 patients currently reporting to a paediatric hospital ED in the USA is diagnosed with a concussion, a proportion that has doubled in the last decade. The number being admitted for concussion, however, has remained relatively constant. This suggests that the incidence of concussion is not increasing in the USA, but rather, patients sustaining concussions with less severe symptoms, who previously may have sought care elsewhere or not at all, are now reporting to EDs after injury. We cannot state this for certain, however, as it is also possible that the incidence of milder injuries has been increasing while more severe concussions requiring admission has remained constant.

Table 2 Most frequent imaging and medication received by concussion patients recorded in the Pediatric Health Information System non-concussion patients recorded in the Pediatric Health Information System

\begin{tabular}{|c|c|c|}
\hline & $\begin{array}{l}\text { Concussion patients } \\
(n=20806)\end{array}$ & $\begin{array}{l}\text { Non-concussion patients } \\
(\mathrm{n}=3915785)\end{array}$ \\
\hline Male, n (\%)* & $13680(65.8 \%)$ & $2103811(53.4 \%)$ \\
\hline \multicolumn{3}{|l|}{$\begin{array}{l}\text { Age category, } n \\
(\%)^{*}\end{array}$} \\
\hline$<1$ year & $580(2.8 \%)$ & $692217(17.7 \%)$ \\
\hline $1-5$ year & $4919(23.6 \%)$ & $1627546(41.6 \%)$ \\
\hline 6-11 year & $6093(29.3 \%)$ & 887175 (22.7\%) \\
\hline 12-18 year & $9214(44.3 \%)$ & $708847(18.1 \%)$ \\
\hline \multicolumn{3}{|c|}{$\begin{array}{l}\text { Insurance category, } \\
\mathrm{n}(\%)^{*}\end{array}$} \\
\hline Private & $10323(49.6 \%)$ & 1091965 (27.9\%) \\
\hline Government & $6354(30.5 \%)$ & 2130772 (54.4\%) \\
\hline Other & $4129(19.8 \%)$ & $693048(17.7 \%)$ \\
\hline
\end{tabular}

\begin{tabular}{lll}
\hline & $\begin{array}{l}\text { Number of } \\
\text { concussion } \\
\text { patients }\end{array}$ & $\begin{array}{l}\text { Percentage of } \\
\text { concussion patients } \\
\text { (95\% Cl) }\end{array}$ \\
\hline $\begin{array}{l}\text { Imaging } \\
\quad \text { Brain CT }\end{array}$ & 12467 & $59.9(59.3$ to 60.6$)$ \\
$\quad$ Cervical spine x-ray & 3085 & $14.8(14.3$ to 15.3$)$ \\
$\quad$ Chest x-ray & 1163 & $5.6(5.3$ to 5.9$)$ \\
$\quad$ Pelvis x-ray & 1067 & $5.1(4.8$ to 5.4$)$ \\
$\quad$ Cervical spine CT & 1008 & $4.8(4.6$ to 5.1$)$ \\
Medications & & \\
$\quad$ Non-narcotic analgesics & 5446 & $26.2(25.6$ to 26.8$)$ \\
$\quad$ Non-steroidal & 3816 & $18.3(17.8$ to 18.9$)$ \\
$\quad$ anti-inflammatory drug & 3179 & $15.3(14.8$ to 15.8$)$ \\
Intravenous fluids & 2966 & $14.3(13.8$ to 14.7$)$ \\
Anti-emetics & 1385 & $6.7(6.3$ to 7$)$ \\
$\quad$ Narcotics &
\end{tabular}


Table 3 The median adjusted costs of visits for concussion at Pediatric Health Information System hospitals

\begin{tabular}{ll}
\hline & $\begin{array}{l}\text { Median adjusted cost per patient, US\$ } \\
(\mathrm{IQR})\end{array}$ \\
\hline $\begin{array}{l}\text { Emergency department (ED) } \\
\text { visits }\end{array}$ & $\$ 462(\$ 238-\$ 809)$ \\
ED visit with CT & $\$ 695(\$ 472-\$ 1009)$ \\
ED visit without CT & $\$ 191(\$ 114-\$ 287)$ \\
Hospitalisation & $\$ 3817(\$ 2386-\$ 6987)$ \\
Hospitalisation with CT & $\$ 4088(\$ 2661-\$ 7290)$ \\
Hospitalisation without CT & $\$ 1907(\$ 1292-\$ 3770)$ \\
\hline
\end{tabular}

Other investigators found similar trends in the number of patients diagnosed with concussion in US EDs. Gilchrist et al found that the number of children seeking treatment for mild TBI between 2001 and 2009 increased by approximately 62\%. ${ }^{7}$ In addition, Bakhos et $a l^{9}$ demonstrated that the number of ED visits for paediatric concussions related to organised sports doubled between 1997 and 2007.

It is unclear, however, whether this increase in ED visits is due to an increased incidence in concussive injuries or simply due to an increased awareness of the potential seriousness of concussion. It is likely that a combination of several new concussion practice guidelines ${ }^{16-19}$ and high-profile cases of National Football League players dying with chronic traumatic encephalopathy, ${ }^{20} 21$ along with the corresponding media attention in the USA surrounding concussion in sports, ${ }^{22-26}$ led to more concussed patients to seek emergent medical care in the mid-2000s. These possible influences in the rise in ED visits for paediatric concussion should also be viewed in the context of prior research demonstrating that healthcare-seeking behaviour in the paediatric population is greatly influenced by parental perception of the seriousness of the injury and the need for reassurance. $^{27-29}$ Furthermore, many states in the USA have enacted laws that require concussion education for coaches and parents or require concussed children to be seen by a physician or other healthcare providers prior to returning to sports. ${ }^{30-33}$ While those laws may contribute to the increase in ED visits demonstrated in our data, most of those laws were passed beginning in 2009, after the steep rise in concussion ED visits that began in 2007..$^{30-33}$ If those laws have led to an increase in ED visits for concussion but resulted in a high number of head CTs, this would point to a possible negative unintended consequence of those laws. This possible relationship and unintended consequence should be further explored.

Previous authors have noted the paucity of evidence guiding the use of medications in the management of concussions. ${ }^{34} 35$ Our study found that medications for pain, including nonsteroidal anti-inflammatory medications, were the most commonly administered. Our data suggest that approximately $1 / 3$ of paediatric concussion patients receive analgesia. The effect of these medications on outcomes remains unknown. We hope our description of the most commonly prescribed medications in paediatric concussion patients in the ED and inpatient setting will stimulate future studies on their effects and any relationship to the need for admission and/or inpatient management and course.

We also found that approximately $60 \%$ of patients with concussion at a paediatric hospital undergo CT imaging of the head. This percentage is slightly lower than reported in a recent study of CT rates for paediatric concussion in the USA. ${ }^{10}$ This may reflect differences in CT use between paediatric and general hospitals. Previous studies have found CT imaging rates for injuries to be lower at paediatric hospitals than general hospitals. $^{36} 37$ Current efforts are underway to reduce CT imaging for mild TBI. Nigrovic et al ${ }^{38}$ compared immediate CT imaging versus observation for children with mild TBI and found that an initial observation period may decrease the need for imaging. If initial observation safely reduces CT imaging, it would avoid radiation exposure and, as this study found, reduce overall costs of a medical visit for concussion; our data show that an ED visit for concussion including CT is more than three times the cost of an ED visit during which CT is not obtained. Balancing the use of extended periods of observation with the potential for decreased use of CT represents another future research opportunity.

Our results vary substantially from the study by Mannix et $a l^{39}$ using PHIS data to describe the use of head CT for assessing minor head injury. Those authors found that head CTs were used in $36 \%$ of patients seen for minor traumatic head injury in PHIS hospital EDs. We believe this discrepancy likely results from the different populations examined. The study by Mannix et al examined a less severe patient population. They excluded any patients admitted as inpatient subsequent to the ED visit and included the broad diagnosis head injury not otherwise specified (ICD-9-CM 959.01), a diagnosis that was specifically excluded in our analyses.

Our findings must be interpreted in light of several limitations. Our study was limited to patients who first presented to the ED, and therefore, did not include any treatment or diagnostic procedures that may have occurred in the outpatient setting. In addition, as PHIS is an administrative database, only limited clinical information is available. Our findings are limited to the accuracy of the ICD-9-CM codes assigned by hospitals. As discussed above, management of paediatric concussion may differ between paediatric and general hospitals, and therefore, our findings may be limited to paediatric hospitals. Furthermore, our findings, especially those regarding the use of CT, may not be generalisable to other countries in part because of international differences in clinical prediction rules used to determine imaging in paediatric minor head injury. ${ }^{40-47}$ Finally, we were unable to differentiate whether pharmaceutical and radiographic interventions took place in the ED or inpatient setting.

Contributors All authors contributed to study conception and design, drafting of the manuscript, and critical revision of the manuscript and approved the final manuscript. MH and CT also contributed to acquisition of the data.

Funding Dr Meehan is supported by award T32 HD040128-06A1 from the National Institutes of Health.

\section{Competing interests None.}

Ethics approval This study was approved by the Institutional Review Board at Children's Mercy Hospitals and Clinics.

Provenance and peer review Not commissioned; externally peer reviewed.

\section{REFERENCES}

1 McCrory P, Meeuwisse WH, Aubry M, et al. Consensus statement on concussion in sport: the 4th International Conference on Concussion in Sport held in Zurich, November 2012. Br J Sports Med 2013;47:250-8.

2 Cantu RC. Consensus statement on concussion in sport-the 3rd International Conference on Concussion, Zurich, November 2008. Neurosurgery 2009:64:786-7.

3 Centers for Disease Control and Prevention. Nonfatal traumatic brain injuries from sports and recreation activities-United States, 2001-2005. MMWR Morb Mortal Wkly Rep 2007:56:733-7.

4 Langlois JA, Rutland-Brown W, Wald MM. The epidemiology and impact of traumatic brain injury: a brief overview. J Head Trauma Rehabil 2006;21:375-8. 
5 Kirkwood MW. Pediatric sport-related concussion: a review of the clinical management of an oft-neglected population. Pediatrics 2006;117:1359-71.

6 Daneshvar DH, Nowinski CJ, McKee AC, et al. The epidemiology of sport-related concussion. Clin Sports Med 2011;30:1-17.

7 Centers for Disease Control and Prevention. Nonfatal traumatic brain injuries related to sports and recreation activities among persons aged $\leq 19$ years-United States, 2001-2009. MMWR Morb Mortal Wkly Rep 2011;60:1337-42.

8 Yang J, Phillips $\mathrm{G}$, Xiang $\mathrm{H}$, et al. Hospitalisations for sport-related concussions in us children aged 5 to 18 years during 2000-2004. Br J Sports Med 2008;42:664-9.

9 Bakhos LL, Lockhart GR, Myers R, et al. Emergency department visits for concussion in young child athletes. Pediatrics 2010;126:e550-6.

10 Meehan WP III, Mannix R. Pediatric concussions in United States emergency departments in the years 2002 to 2006. J Pediatr 2010;157:889-93.

11 Thurman D, Guerrero J. Trends in hospitalization associated with traumatic brain injury. JAMA 1999;282:954-7.

12 Grubenhoff JA, Kirkwood M, Gao D, et al. Evaluation of the standardized assessment of concussion in a pediatric emergency department. Pediatrics 2010;126:688-95.

13 Peterson SE, Stull MJ, Collins MW, et al. Neurocognitive function of emergency department patients with mild traumatic brain injury. Ann Emerg Med 2009:53:796-803 e1.

14 Shah SS, Hall M, Newland JG, et al. Comparative effectiveness of pleural drainage procedures for the treatment of complicated pneumonia in childhood. J Hosp Med 2011;6:256-63.

15 Weiss AK, Hall M, Lee GE, et al. Adjunct corticosteroids in children hospitalized with community-acquired pneumonia. Pediatrics 2011;127:e255-63.

16 Guskiewicz KM, Bruce SL, Cantu RC, et al. National athletic trainers' association position statement: management of sport-related concussion. J Athletic Train 2004;39:280-97.

17 McCrory P. Summary and agreement statement of the 2nd International Conference on Concussion in Sport, Prague 2004. Br J Sports Med 2005;39(Suppl 1):i78-86.

18 Carson J, Tator $C$, Johnston $\mathrm{K}$, et al. New guidelines for concussion management. Can Fam Physician 2006;52:756-7.

19 Concussion (mild traumatic brain injury) and the team physician: a consensus statement. Med Sci Sports Exerc 2006;38:395-9.

20 Omalu BI, DeKosky ST, Minster RL, et al. Chronic traumatic encephalopathy in a national football league player. Neurosurgery 2005;57:128-34.

21 Omalu BI, DeKosky ST, Hamilton RL, et al. Chronic traumatic encephalopathy in a national football league player. Neurosurgery 2006;59:1086-92.

22 Bowser B. New research raises questions on how to treat concussion "epidemic" [transcript]: NewsHour; 2007.

23 Fackelmann K. Football players cautioned not to rush back after a concussion. USA Today 18 November 2003.

24 MacMullan J. I don't want anyone to end up like me. The Boston Globe 2 February 2007

25 Meadows B. Concussions: is football too dangerous? People Magazine 8 October 2007:107-10.

26 Schwarz A. Silence on concussions raises risks of injury. New York Times 15 September 2007

27 Williams A, O'Rourke P, Keogh S. Making choices: why parents present to the emergency department for non-urgent care. Arch Dis Child 2009;94:817-20.

28 Hendry SJ, Beattie TF, Heaney D. Minor illness and injury: factors influencing attendance at a paediatric accident and emergency department. Arch Dis Child 2005:90:629-33.
29 Truman CD, Reutter L. Care-giving and care-seeking behaviours of parents who take their children to an emergency department for non-urgent care. Can J Public Health 2002:93:41-6.

30 Adler RH, Herring SA. Changing the culture of concussion: education meets legislation. PMRJ 2011;3(S2):S468-70.

31 Rivara FP. Concussion: time to start paying attention. Arch Pediatr Adolesc Med 2012;166:666-7.

32 Schatz P, Moser RS. Current issues in pediatric sports concussion. Clin Neuropsychol 2011:25:1042-57.

33 Lueke L. High school athletes and concussions: more than a game at stake. J Leg Med 2011;32:483-501.

34 McCrory P. Should we treat concussion pharmacologically? The need for evidence based pharmacological treatment for the concussed athlete. Br J Sports Med 2002;36:3-5.

35 Halstead ME, Walter KD, Council on Sports Medicine and Fitness. American academy of pediatrics. Clinical report-sport-related concussion in children and adolescents. Pediatrics 2010;126:597-615.

36 Mannix R, Bourgeois FT, Schutzman SA, et al. Neuroimaging for pediatric head trauma: do patient and hospital characteristics influence who gets imaged? Acad Emerg Med 2010;17:694-700

37 Mannix R, Nigrovic LE, Schutzman SA, et al. Factors associated with the use of cervical spine computed tomography imaging in pediatric trauma patients. Acad Emerg Med 2011;18:905-11.

38 Nigrovic LE, Schunk JE, Foerster A, et al. The effect of observation on cranial computed tomography utilization for children after blunt head trauma. Pediatrics 2011;127:1067-73.

39 Mannix R, Meehan WP, Monuteaux MC, et al. Computed tomography for minor head injury: variation and trends in major united states pediatric emergency departments. J Pediatr 2012;160:136-9.e1.

40 Osmond MH, Klassen TP, Wells GA, et al. Catch: a clinical decision rule for the use of computed tomography in children with minor head injury. CMAJ 2010;182:341-8.

41 Kuppermann N, Holmes JF, Dayan PS, et al. Identification of children at very low risk of clinically-important brain injuries after head trauma: a prospective cohort study. Lancet 2009;374:1160-70.

42 Dunning J, Daly JP, Lomas J-P, et al. Derivation of the children's head injury algorithm for the prediction of important clinical events decision rule for head injury in children. Arch Dis Child 2006;91:885-91.

43 Dalt L, Marchi AG, Laudizi L, et al. Predictors of intracranial injuries in children after blunt head trauma. Eur J Pediatr 2005;165:142-8.

44 Müller K, Waterloo K, Romner B, et al. Mild head injuries: impact of a national strategy for implementation of management guidelines. J Trauma 2003:55:1029-34.

45 Lockie FD, Dalton S, Oakley E, et al. Triggers for head computed tomography following paediatric head injury: comparison of physicians' reported practice and clinical decision rules. Emerg Med Australas 2012;25:75-82.

46 Crowe L, Anderson V, Babl FE. Application of the chalice clinical prediction rule for intracranial injury in children outside the UK: impact on head ct rate. Arch Dis Child 2010;95:1017-22.

47 Maguire JL, Boutis K, Uleryk EM, et al. Should a head-injured child receive a head ct scan? A systematic review of clinical prediction rules. Pediatrics 2009;124: e145-54. 